\title{
Fast Determination of Manganese in Milk and Similar Infant Food Samples Using Multivariate Optimization and GF AAS
}

\author{
Flávia Regina de Amorim, ${ }^{1}$ Clésia Cristina Nascentes, ${ }^{1}$ \\ Milton Batista Franco, ${ }^{2}$ and José Bento Borba da Silva ${ }^{1}$ \\ ${ }^{1}$ Department of Chemistry, Federal University of Minas Gerais, 31.270-901 Belo Horizonte, MG, Brazil \\ ${ }^{2}$ Centro de Desenvolvimento da Tecnologia Nuclear, Comissão Nacional de Energia Nuclear, 31.270-901 Belo Horizonte, MG, Brazil
}

Correspondence should be addressed to Clésia Cristina Nascentes, clesia@qui.ufmg.br

Received 14 May 2011; Revised 4 August 2011; Accepted 9 August 2011

Academic Editor: Edenir R. Pereira-Filho

Copyright (C) 2011 Flávia Regina de Amorim et al. This is an open access article distributed under the Creative Commons Attribution License, which permits unrestricted use, distribution, and reproduction in any medium, provided the original work is properly cited.

\begin{abstract}
Manganese is an essential element, but high levels in foods can be toxic mainly for children. A fast and efficient method to determine $\mathrm{Mn}$ in milk and other infant foods using slurries and liquid samples is presented. Slurries were prepared in ultrapure water with 10 minutes of sonication. Liquid samples were diluted in ultrapure water when necessary. Multivariate optimization was used to establish some optimal analytical parameters through a fractional factorial design and a central composite design. Slurred and diluted samples were analyzed directly by GF AAS. The method presented limit of detection of $(0.98 \pm 0.04) \mu \mathrm{g} \mathrm{L}{ }^{-1}$, characteristic mass of $(2.9 \pm 0.3) \mathrm{pg}$ (recommended value $2 \mathrm{pg}$ ), RSD of $2.3 \%(n=5)$, and linear range from 0.98 to $20.0 \mu \mathrm{g} \mathrm{L}^{-1}$ using iridium as permanent modifier. The accuracy was evaluated analyzing two certified reference materials: nonfat milk powder (SRM1549) and whole milk powder (SRM8435). The powdered samples concentrations were between 0.210 and $26.3 \mu \mathrm{g} \mathrm{g}^{-1}$.
\end{abstract}

\section{Introduction}

$\mathrm{Mn}$ is an essential trace element that is present in all living cells. The human body in normal conditions contains about 10 to $20 \mathrm{mg}$ of $\mathrm{Mn}$, and it is present in numerous oxidoreductases and other enzymes exercising several biological functions $[1,2]$. A daily ingestion of at least $3 \mathrm{mg}$ is considered as necessary [2]. Although Mn is considered an essential element, the data are insufficient to settle down a value for the daily ingestion [3].

The fetal life and the first childhood are the most vulnerable periods to the Mn deficiency although rare [4]. This can cause dermatitis, problems in the glucose metabolism and of proteins, mitochondria abnormalities, infertilities, bad formation of the bones, decrease of the serum cholesterol, and others [5]. Although the Mn gastrointestinal absorption is only 3 to $5 \%$, foods constitute the largest source of $\mathrm{Mn}$ in general for the population, and they are also the primary source of the absorbed metal [3]. The levels of daily alimentary ingestion estimated appropriate for 3-10-yearold age group is ranged of 1.0 to $2.0 \mathrm{mg} \mathrm{day}^{-1}$; over 10 years, it is ranged from 2.0 to $5.0 \mathrm{mg}$ day $^{-1}$; of 6 months to 1 year it is ranged of 0.6 to $1.0 \mathrm{mg} \mathrm{day}^{-1}$, and until 6 months, it is ranged from 0.3 to $0.6 \mathrm{mg} \mathrm{day}^{-1}[3]$.

Excess of Mn can be toxicant and the nervous system seems to be the most vulnerable [6]. The Mn neurotoxicity in adults is associated with symptoms of Parkinson disease while effects in children are not well characterized. Babies and children are quite sensitive to the Mn toxicity. Neonates accumulate more $\mathrm{Mn}$ than adults due to larger absorption of Mn [7]. The Mn concentration in milk and similar products vary from 0.02 to $0.49 \mu \mathrm{g} \mathrm{g}^{-1}$ [3]. Erikson and workers [6] reported that $\mathrm{Mn}$ concentration in human milk ranged from 3 to $6 \mu \mathrm{g} \mathrm{L}^{-1}$ while in bovine milk the Mn concentrations being about $21 \mu \mathrm{g} \mathrm{L}^{-1}$. Human milk usually had a lower concentration while the infant formula content can vary drastically. In this case, the soy food deserves special attention. The plants absorb $\mathrm{Mn}$ in form of divalent ion [8], and the soy could concentrate it in its grains. A feeding bottle of soy drink can contain a Mn concentration many times higher than that found in the breast or cow milk. 
Therefore, the information on the Mn levels in this infant food is extremely important in assessing the risk to human health.

Due to its low concentrations in a variety of food samples, Mn determination requires an accurate analytical method with sufficient sensitivity. Electrothermal atomic absorption spectrometry (ET AAS) and plasma techniques have been widely used for total Mn determination in several types of food samples. Most analytical techniques for metal determination need a sample preparation method which involves solubilization with complete or partial decomposition of the matrix, and most methods make use of acids with oxidizing properties. Manganese and other metals were determined in 30 samples of human colostrum of Turkey's mothers by GF AAS with Zeeman background correction after wet-ashing decomposition finding mean $43.2 \mu \mathrm{g} \mathrm{L}^{-1}$ and levels varying from 12.5 to $70.7 \mu \mathrm{g} \mathrm{L}^{-1}$ [9]. Leotsinidis et al. [10] determined Mn by GF AAS in 180 samples of human colostrum-finding levels ranging from 1.01 to $15.70 \mu \mathrm{g} \mathrm{L}^{-1}$.

Several methods of slurry sampling have been frequently studied in order to minimize drawbacks of the digestion procedures, such as long analysis times, high cost, analyte loss or contamination and to get better limits of detection and sensitivity of the methods. A method was developed for analysis of $\mathrm{Ca}, \mathrm{Cu}, \mathrm{Fe}, \mathrm{K}, \mathrm{Mg}, \mathrm{Mn}, \mathrm{Na}, \mathrm{P}$, and $\mathrm{Zn}$ in infant formulas, milk powders, and liquid milk using slurry samples, ICP OES operating radially, and determination against aqueous standards [11]. The method was found to be suitable for routine quality control monitoring of infant formulas and milk powders, thereby improving sample throughput and analytical confidence. Matusiewicz and Golik [12] utilized a slurry-sampling technique for simultaneous multielement analysis of $\mathrm{Na}, \mathrm{K}, \mathrm{Ca}, \mathrm{Mg}, \mathrm{P}$ and $\mathrm{Cd}, \mathrm{Cu}, \mathrm{Mn}, \mathrm{Sr}, \mathrm{Zn}$ by microwave-induced plasma optical emission spectrometry (MIP-OES). The method offered relatively good precision with measured concentrations being in satisfactory agreement with certified values for several samples including milk powder. ET AAS technique was employed to analyze samples of dairy products processed with a slurry procedure to minimize sample pretreatment. The accuracy and precision of the method were verified. In analyzed samples, mean value ranged from 0.010 to $0.900 \mu \mathrm{g} \mathrm{g}^{-1}$ for $\mathrm{Mn}$, and the highest levels were found in children's milk [13].

Innumerous parameters of analytical conditions can be optimized by multivariate methods using experimental designs. Some works have been reported in order to determine optimal analytical parameters in spectroscopy especially in GF AAS [14-17]. A multivariate optimization is executed to evaluate the variables and the interactions that have significant influence on the response and to determine the optimal values of the experimental variables, and the interactions among its that have significant influence on the response in opposition to univariate optimization [16]. Univariate optimization was generally carried out by procedures that evaluate the effect of just one variable on time; therefore, it does not allow the establishment of true optimal values, mainly due to close connections that may exist among the studied variables [18]. Another advantage of multivariate optimization methods is the smaller number of experiments becoming analytical optimization cost lower.

This work proposes a new application of GF AAS in the direct determination of $\mathrm{Mn}$, in milk samples and other food samples like soy food, infant formula, and breast milk. In the course of the paper, some problems related to this procedure are discussed, especially those associated to the matrix interferences and calibration method choice. Also, studies about chemical modification approach and the use of a multivariate optimization strategy based on a fractional factorial design and on a central composite design for setting pyrolysis and atomization temperatures are presented.

\section{Experimental}

2.1. Instrumentation. A Perkin Elmer (Norwalk, Conn, USA) AAnalyst 300 atomic absorption spectrometer equipped with an HGA 800 graphite furnace and an AS-72 autosampler was used in all measurements of Mn-integrated absorbance. Background correction was made with a continuum light source (deuterium lamp). Argon 99.996\% (White Martins, São Paulo, SP, Brazil) was used as purge gas at 250- $\mathrm{mL} \mathrm{min}^{-1}$. Perkin Elmer pyrolytic graphite-coated tubes with L'vov platforms were used. A manganese hollow cathode lamp (Perkin Elmer) operating at wavelength $279.5 \mathrm{~nm}$ with slit width of $0.2 \mathrm{~nm}$ and current of $25 \mathrm{~mA}$ (conditions recommended by the manufacturer) was used. The multivariate optimization process was carried out by using statistical software Statistica 6.0 .

2.2. Reagents, Materials, Solutions, and Certified Reference

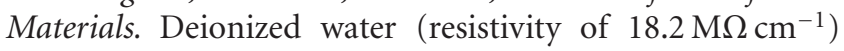
was obtained with a Milli-Q System (Millipore, Bedford, Mass, USA), and it was purified immediately before use in preparing all solutions. Nitric acid was obtained from Merck (Darmstadt, Germany). Iridium, niobium, tantalum, ruthenium, rhodium, and zirconium $1000 \mathrm{mg} \mathrm{L}^{-1}$ solution was from Fluka (Buchs, Switzerland). Zirconium $1000 \mathrm{mg} \mathrm{L}^{-1}$ solution was from Aldrich (Milwaukee, Wis, USA). Tungsten $1000 \mathrm{mg} \mathrm{L}^{-1}$ solution was prepared by dissolving $0.18 \mathrm{~g}$ of $\mathrm{Na}_{2} \mathrm{WO}_{4}$ (Merck) in $100 \mathrm{~mL}$ of water. Plastic bottles, autosampler cups, and glassware were cleaned by soaking in $20 \% \mathrm{v} / \mathrm{v} \mathrm{HNO}_{3}$ for one day, rinsing many times with Milli-Q water and drying. The autosampler washing solution containing $0.05 \% \mathrm{v} / \mathrm{v}$ Triton X-100 (Merck) plus $0.1 \%(\mathrm{v} / \mathrm{v})$ isopropanol (Sigma-Aldrich, São Paulo, Brazil) was used to avoid analyte adsorption onto the surface of the container and clogging of the capillary sampling tip, as well as to improve the dispersion of sample solution onto the platform.

Manganese stock solution $\left(1000 \mathrm{mg} \mathrm{L}^{-1}\right)$ was prepared from Titrisol Merck in 5\% v/v nitric acid. Cetyl trimethyl ammonium chloride (CTAC) $0.1 \% \mathrm{v} / \mathrm{v}$ solution was prepared from a $25 \% \mathrm{v} / \mathrm{v}$ aqueous stock solution from FeF Chemicals (Koge, Denmark). CTAC acts as a detergent to minimize the formation of carbonaceous resides inside the graphite tube and also help the cleaning of the autosampler capillary between the sampling. NIST-certified reference materials 
TABLE 1: Temperature program used in optimization method.

\begin{tabular}{lcccc}
\hline Step & $\begin{array}{c}\text { Temperature } \\
\left({ }^{\circ} \mathrm{C}\right)\end{array}$ & $\begin{array}{c}\text { Ramp } \\
\text { time }(\mathrm{s})\end{array}$ & $\begin{array}{c}\text { Hold time } \\
(\mathrm{s})\end{array}$ & $\begin{array}{c}\text { Ar flow rate } \\
\left(\mathrm{mL} \mathrm{min}^{-1}\right)\end{array}$ \\
\hline Drying & 90 & 5 & 15 & 250 \\
Drying & 140 & 5 & 60 & 250 \\
Pyrolysis & $\mathrm{a}$ & 10 & $\mathrm{c}$ & 250 \\
Atomization & $\mathrm{b}$ & 0 & 5 & 0 (read) \\
Clean & 2700 & 1 & 5 & 250 \\
Cool & 20 & 1 & 10 & 250 \\
\hline
\end{tabular}

a,b,c Variables optimized.

were used, nonfat milk powder (SRM 1549) and whole milk powder (SRM 8435).

2.3. Sampling and Sample Preparation. Whole and skimmed milk, infant formula, milk-based drink, and soy drink samples were obtained from a local store in Brazil. Powdered samples were prepared by dissolving the milk powder using ultrapure water, following the instructions of the manufacturer; usually at $15 \% \mathrm{w} / \mathrm{v}$. Milk samples were sonicated for $10 \mathrm{~min}$ in order to stabilize the slurries after optimization of the sonication time. Liquid samples were used in natura, or they were diluted if it was necessary. All samples were stored at about $10^{\circ} \mathrm{C}$ until treatments were performed. The sample injection volume used was $20 \mu \mathrm{L}$.

2.4. Graphite Tube Treatment. Each L'vov platform was treated independently with $500 \mu \mathrm{g}$ of the studied modifiers by applying $25 \mu \mathrm{L}$ of each metal solution $\left(1000 \mathrm{mg} \mathrm{L}^{-1}\right)$ onto the platform and submitting it to a furnace temperature program 20 times as previously described [19].

2.5. Optimization Strategies. A diluted $1+1$ whole milk sample was employed in all optimization steps. Several integrated absorbance measures and background signal of this sample were accomplished in manufacturer's recommended conditions using $20 \mu \mathrm{L}$ volumes in presence of several chemical permanent modifiers: $\mathrm{W}, \mathrm{Rh}, \mathrm{Ir}, \mathrm{Zr}, \mathrm{Nb}, \mathrm{Ta}$, and $\mathrm{Ru}$. A tube without permanent modifier was employed too. The best sensitivity, repeatability, and lowest background signal were observed in order to choose the appropriate modifier; in this case, it was Ir. Then two experimental designs were carried out to evaluate the influence and interactions among the variables studied and determine the optimal experimental conditions. In the first experimental design (a fractional factorial design $2^{3-1}, 8$ experiments, and duplicate), the factors studied were pyrolysis hold time of 20 and $60 \mathrm{~s}$, pyrolysis temperatures of 1000 and $1800^{\circ} \mathrm{C}$, and atomization temperatures of 2000 and $2600^{\circ} \mathrm{C}$. The other parameters of the temperature program are presented in Table 1. Based on the results obtained in the first experimental design, pyrolysis hold time was fixed, and the optimal pyrolysis and atomization temperatures were determined through a central composite design (Table 2).

In optimized conditions, proposed method was validated. In this step were evaluated matrix effects, linear range, limits of detection and quantification, and precision and accuracy.

2.6. General Procedure. The established method was used for the determination of $\mathrm{Mn}$ in 27 infant food samples. Solubilized milk samples $(15 \% \mathrm{w} / \mathrm{v})$ were sonicated to $10 \mathrm{~min}$ and diluted 1:1 with deionized water. A volume of $20.0 \mu \mathrm{L}$ was injected in the graphite furnace treated previously with $500 \mu \mathrm{g}$ Ir (permanent modifier), and the temperature program optimized was performed.

\section{Results and Discussion}

3.1. Modifier Choice. Use of modifier in GFAAS is important to increase the thermal stability of analytes so that higher pyrolysis temperatures can be used to volatilize the higher matrix components and to decrease background signals of real samples [20]. Higher sensitivity and good precision were obtained with Ir (Figure 1). Moreover, lower background signal was reached with this permanent modifier.

3.2. Statistical Analysis. The pyrolysis and atomization steps are critical in GF AAS determination, and they contribute largely to a sensitivity increase and reduction of the background absorption if carefully optimized together with appropriate modifier. The results of the fractional factorial design showed that the significant variables were pyrolysis temperature and atomization through Pareto's chart of the estimate effects at 95\% confidence level (Figure 2). It means that only these two variables presented significant effects on the response (integrated absorbance). After this study, a response surface methodology through a central composite design (CCD) with these two significant independent variables was accomplished to determine the optimal conditions and critical points of these variables (Table 2). An evaluation of the variables effects on the response and their interactions was done starting from those results. Pyrolysis and atomization temperatures and the interactions between each one of these showed the more significant effects (Figure 3). A quadratic model (1) was obtained after test for adequacy and fitness by analysis of variance (ANOVA)

$$
\begin{aligned}
A= & 0.959488+\left(2.3486 \times 10^{-3}\right)(\mathrm{PT})-\left(1.1247 \times 10^{-6}\right) \\
& \times(\mathrm{PT})^{2}-\left(1.7109 \times 10^{-3}\right)(\mathrm{AT})+\left(4.2256 \times 10^{-7}\right) \\
& \times(\mathrm{AT})^{2}+\left(6.9444 \times 10^{-9}\right)(\mathrm{PT})(\mathrm{AT}),
\end{aligned}
$$

where $A$ is the integrated absorbance, $\mathrm{PT}$ is pyrolysis temperature, and AT is atomization temperature. The critical points were calculated from $[\delta A / \delta(T P)]=1050^{\circ} \mathrm{C}$ and $[\delta A / \delta(T A)]=2030^{\circ} \mathrm{C}$; however, they mean a minimum point indicating lowest sensitivity.

The fitted polynomial equation was expressed as surface and contour plots in order to visualize the optimal conditions (Figure 4). Observing the response surface, it shows that only the pyrolysis temperature showed a maximum value, suggesting a design's expansion for the investigation of 


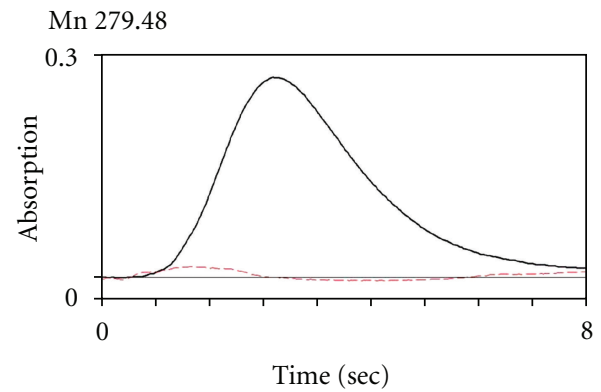

PK Ht-AA: 0.2689A BG: 0.0147 A

Pk Area-AA: 0.7490A-s BG: 0.0219 A-s

(a)

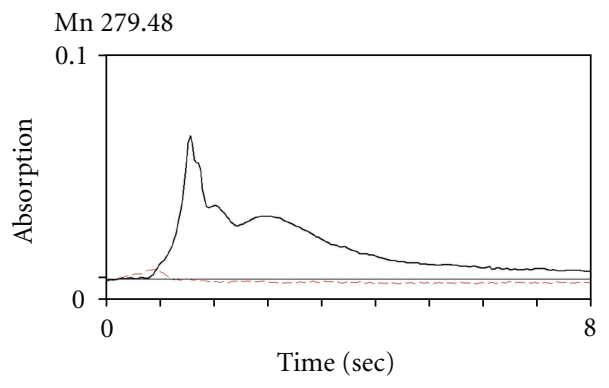

PK Ht-AA: 0.0836A BG: $0.0054 \mathrm{~A}$

Pk Area-AA: 0.1068A-s BG: -0.0076 A-s

(c)

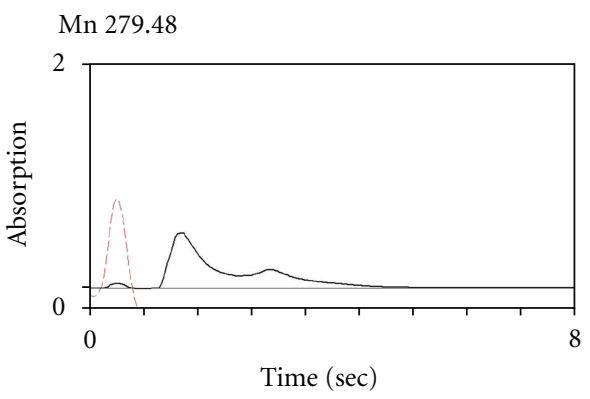

PK Ht-AA: 0.536 A BG: $1.0134 \mathrm{~A}$

Pk Area-AA: 0.5147 A-s BG: -3.1761 A-s

(e)

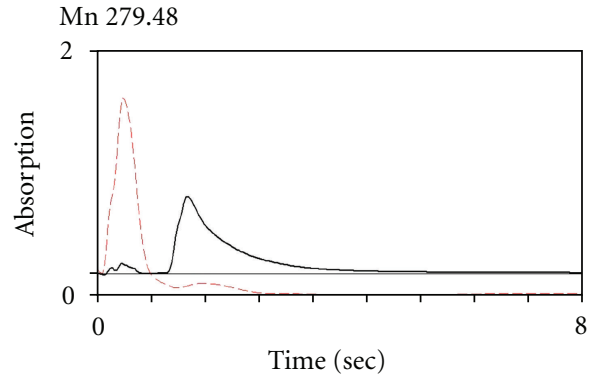

PK Ht-AA: 0.7420A BG: 1.7733 A

Pk Area-AA: 0.6598A-s BG: -0.5738 A-s

(b)

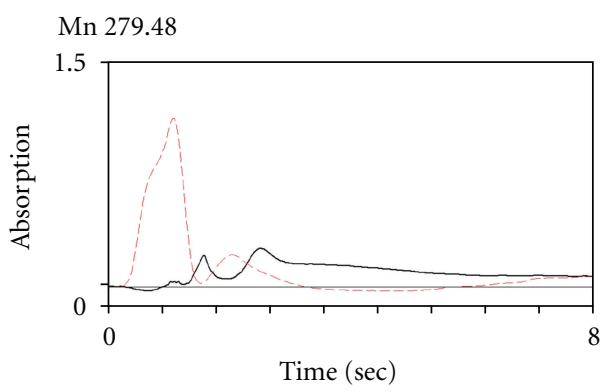

PK Ht-AA: 0.2561 A BG: 1.1165 A

Pk Area-AA: 0.7259A-s BG: 0.9091 A-s

(d)

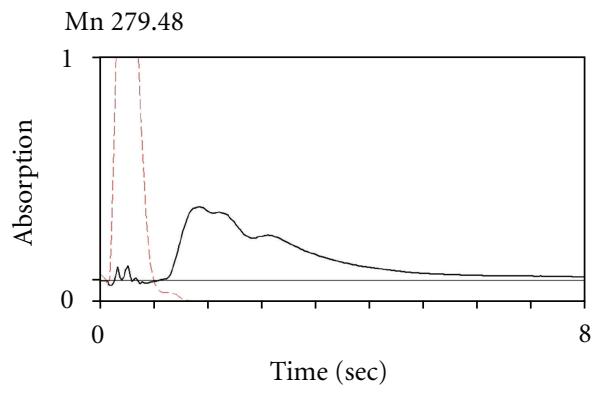

PK Ht-AA: 0.334 A BG: 2.3234 A

Pk Area-AA: 0.6925A-s BG:-0.1826 A-s

(f)

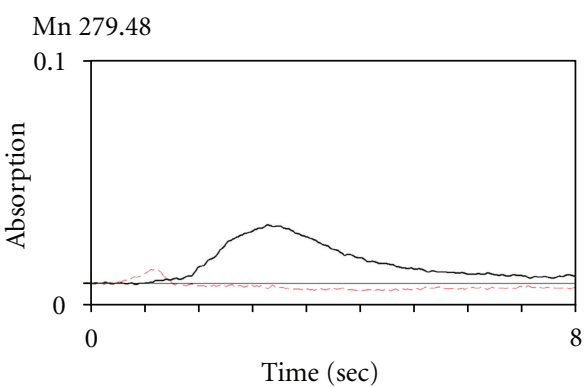

PK Ht-AA: 0.0270A BG: 0.0078 A

Pk Area-AA: 0.0706A-s BG: -0.0092 A-s

(g)

FIgURE 1: Peak profile (-) and background (- - ) obtained in whole milk sample diluted 1:1 using different permanent modifier: (a) Ir, (b) $\mathrm{Nb}$, (c) Rh, (d) Ru, (e) Ta, (f) Zr, and (g) W. 
TABLE 2: Experiments and results obtained in second experimental design to determine Mn in milk and similar food samples.

\begin{tabular}{lcccc}
\hline Exp. & ${ }^{a}$ Pyrolysis temperature $\left({ }^{\circ} \mathrm{C}\right)$ & ${ }^{a}$ Atomization temperature $\left({ }^{\circ} \mathrm{C}\right)$ & Integrated absorbance $(\mathrm{s})$ & Background signal $(\mathrm{s})$ \\
\hline 1 & $1000(-1)$ & $2000(-1)$ & $0.478 \pm 0.003$ & $0.076 \pm 0.005$ \\
2 & $1000(-1)$ & $2600(+1)$ & $0.618 \pm 0.060$ & $-0.085 \pm 0.097$ \\
3 & $1600(+1)$ & $2000(-1)$ & $0.060 \pm 0.004$ & $-0.083 \pm 0.007$ \\
4 & $1600(+1)$ & $2600(+1)$ & $0.202 \pm 0.015$ & $-0.233 \pm 0.001$ \\
5 & $876(-\sqrt{2})$ & $2300(0)$ & $0.441 \pm 0.031$ & $0.079 \pm 0.027$ \\
6 & $1724(\sqrt{2})$ & $2300(0)$ & $0.082 \pm 0.001$ & $-0.133 \pm 0.032$ \\
7 & $1300(0)$ & $1876(-\sqrt{2})$ & $0.434 \pm 0.001$ & $0.033 \pm 0.040$ \\
8 & $1300(0)$ & $2724(\sqrt{2})$ & $0.646 \pm 0.039$ & $-0.113 \pm 0.068$ \\
$9(\mathrm{C})$ & $1300(0)$ & $2300(0)$ & $0.443 \pm 0.018$ & $0.017 \pm 0.082$ \\
$10(\mathrm{C})$ & $1300(0)$ & $2300(0)$ & $0.424 \pm 0.018$ & $-0.045 \pm 0.002$ \\
\hline
\end{tabular}

${ }^{\mathrm{a}}$ The coded values are between parenthesis.

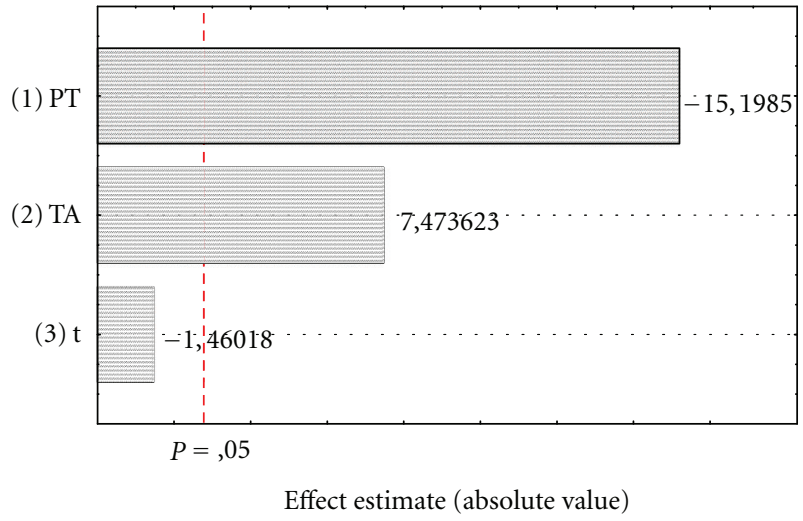

Figure 2: Pareto chart obtained from fractional factorial design in the optimization to Mn determination by GFAAS.

atomization temperatures over $2800^{\circ} \mathrm{C}$. This condition is inadequate in having measured for GF AAS because the high temperature could decrease the lifetime of graphite tube. With analysis of the contour surface (Figure 4), it was possible to outline the problem and to establish the conditions of good sensitivity of the method without reducing the useful lifetime of the graphite tube, pyrolysis temperature of $1000^{\circ} \mathrm{C}$ and atomization temperature of $2600^{\circ} \mathrm{C}$. Analyzing the contour graph of the background signal (not shown), we confirmed that in conditions of PT of $1000^{\circ} \mathrm{C}$ and $\mathrm{AT}$ of $2600^{\circ} \mathrm{C}$, there were no problems with background absorption because in these conditions the module of the background signal approximated to zero, is corrected.

3.3. Analytical Parameters of Merit. Using the optimal experimental conditions determined $\left(\mathrm{PT}=1000^{\circ} \mathrm{C}, \mathrm{AT}=\right.$ $2600^{\circ} \mathrm{C}$, time $=30 \mathrm{~s}$, and iridium as permanent modifier), the analytical parameters of merit were obtained (Table 3 ). Aqueous calibration curves and analyte addition calibration curves were built on water, soy drink, breast milk, skimmed milk, and whole milk on at least five levels of concentration. Statistical tests ( $F$ and $t$ at $95 \%$ confidence level) were applied to compare slopes of aqueous and analyte addition
TABLE 3: Analytical parameters of merit.

\begin{tabular}{|c|c|c|}
\hline Parameters & Units & Values \\
\hline Linear range & $\mu \mathrm{g} \mathrm{L}^{-1}$ & $0.0-20.0$ \\
\hline$r$ & - & $0.9959 \pm 0.0015$ \\
\hline Characteristic mass ${ }^{\mathrm{a}}, \mathrm{m}_{\mathrm{o}}$ & pg & $2.9 \pm 0.3$ \\
\hline Limit of detection, LD & $\mu \mathrm{g} \mathrm{L}^{-1}$ & $0.98 \pm 0.04$ \\
\hline Limit of detection, LD & $\mu \mathrm{gg}^{-1}$ & $19.6 \pm 0.8$ \\
\hline Limit of quantification, LQ & $\mu \mathrm{g} \mathrm{L}^{-1}$ & $3.23 \pm 0.19$ \\
\hline Limit of quantification, LQ & $\mu \mathrm{g} \mathrm{kg}^{-1}$ & $64.6 \pm 3.8$ \\
\hline Precision $(\% \mathrm{RSD})^{\mathrm{b}}$ & $\%$ & 2.3 \\
\hline Accuracy $(\text { SRM } 8435)^{c}$ & $\mu \mathrm{gg}^{-1}$ & $0.16 \pm 0.04$ \\
\hline Accuracy $\left(\right.$ SRM 1549) ${ }^{\mathrm{d}}$ & $\mu \mathrm{gg}^{-1}$ & $0.26 \pm 0.05$ \\
\hline
\end{tabular}

${ }^{a}$ Recommended value $2.0 \mathrm{pg}$.

${ }^{\mathrm{b}}$ Concentration of $10 \mu \mathrm{g} \mathrm{L}-1, n=5$

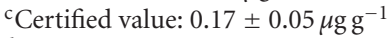

${ }^{\mathrm{d}}$ Certified value $0.26 \pm 0.06 \mu \mathrm{g} \mathrm{g}^{-1}$.

calibration curves and results show that matrix effect was not verified in this study. The instrumental limit of detection $\left(0.98 \pm 0.04 \mu \mathrm{g} \mathrm{L}^{-1}\right)$ and limit of quantification $(3.23 \pm$ $0.19 \mu \mathrm{g} \mathrm{L}^{-1}$ ) was calculated by IUPAC criterion, according to $\mathrm{LOD}=3 s_{\text {blank }}, n=10 /$ slope and LOQ $=10 s_{\text {blank}}$, $n=10 /$ slope. The sensitivity was evaluated calculating the characteristic mass $(2.9 \pm 0.3 \mathrm{pg})$ and comparing to the recommended values (2 pg). Comparatively, Hsiang et al. [21] determined $\mathrm{Mn}$ in urine by a multielement graphite furnace atomic absorption spectrometer obtaining characteristics mass of $7.1 \mathrm{pg}$ being $6.3 \mathrm{pg}$ the manufacturer's data. The linearity was estimated by constructing aqueous calibration curve in 0.0 to $50.0 \mu \mathrm{g} \mathrm{L}^{-1}$ range, and a linear range was verified from 0.98 to $20.0 \mu \mathrm{g} \mathrm{L}^{-1}(r>$ $0.99)$. The accuracy was demonstrated by measuring $\mathrm{Mn}$ concentration in two certified materials of milk, obtaining concentration statistically similar to the certified values (Table 3 ). The repeatability was evaluated by calculating the relative standard deviation of 5 replicates of standard solutions containing $10 \mu \mathrm{g} \mathrm{L}^{-1}$, and values lower than $3 \%$ were obtained. 


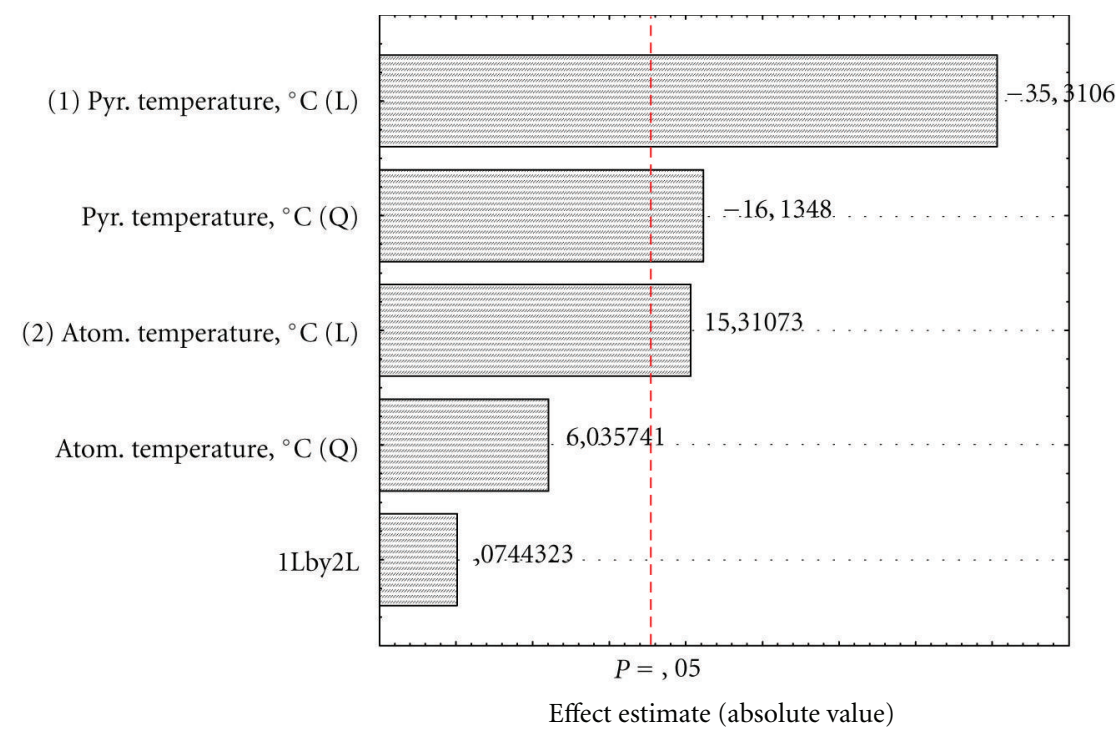

FIGURE 3: Pareto chart obtained from Compost Central Design in the optimization to Mn determination by GFAAS.
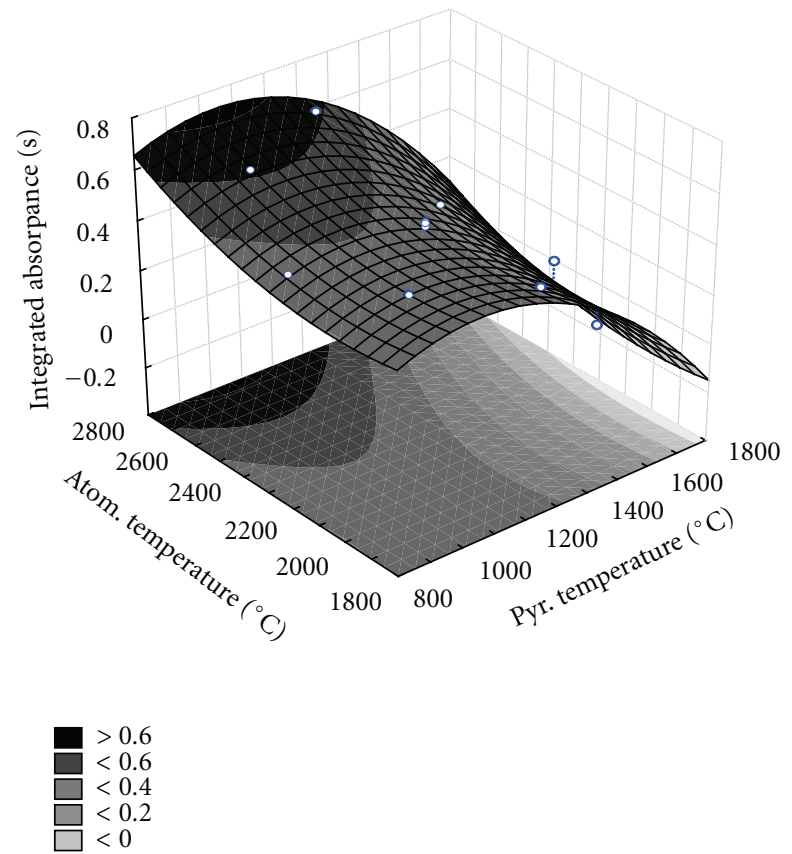

FIGURE 4: Response surface plot obtained from Compost Central Design in the optimization to Mn determination by GFAAS.

3.4. Determination of $\mathrm{Mn}$ in Milk and Similar Infant Food Samples. The results of analysis of milk and similar infant food samples are shown in Table 4. The lowest and highest sample Mn levels in $\mu \mathrm{g} \mathrm{g}^{-1}$ were in whole milk, 0.35 and 0.90 $(n=4)$; in milk-based drink, 0.21 and $0.48(n=3)$; in skimmed, milk 0.29 and $0.68(n=2)$; in infant formula, 0.73 and $19.82(n=6)$; in soy-based drink, 3.16 and 26.32 ( $n=4)$; in goat milk, $0.52(n=1)$. The Mn content was higher in soy-based drinks and infant formulas (Table 4). Considering a consume of four feeding bottles by day ( $150 \mathrm{~g}$
TABLE 4: Manganese concentration in milk and similar food samples determined by proposed method $(n=3)$.

\begin{tabular}{lcc}
\hline Sample & $\begin{array}{c}\text { Mn concentration, } \\
\mu \mathrm{g} \mathrm{g}^{-1}\end{array}$ & $\begin{array}{c}\text { Mn intake by day, } \\
\mathrm{mg}^{\mathrm{a}}\end{array}$ \\
\hline Whole milk A & $0.900 \pm 0.080$ & 0.135 \\
Whole milk B & $0.750 \pm 0.080$ & 0.113 \\
Whole milk C & $0.830 \pm 0.080$ & 0.125 \\
Whole milk D & $0.350 \pm 0.020$ & 0.053 \\
Milk-based drink A & $0.480 \pm 0.050$ & 0.072 \\
Milk-based drink B & $0.310 \pm 0.020$ & 0.047 \\
Milk-based drink C & $0.210 \pm 0.020$ & 0.032 \\
Skimmed milk A & $0.290 \pm 0.040$ & 0.044 \\
Skimmed milk B & $0.68 \pm 0.08$ & 0.102 \\
Infant formula A & $0.730 \pm 0.020$ & 0.110 \\
Infant formula B & $1.28 \pm 0.11$ & 0.192 \\
Infant formula C & $19.8 \pm 2.1$ & 2.97 \\
Infant formula D & $1.08 \pm 0.08$ & 0.162 \\
Infant formula E & $0.940 \pm 0.030$ & 0.141 \\
Infant formula F & $0.86 \pm 0.01$ & 0.129 \\
Soy-based drink A & $11.5 \pm 0.5$ & 1.72 \\
Soy-based drink B & $3.16 \pm 0.12$ & 0.474 \\
Soy-based drink C & $9.75 \pm 0.06$ & 1.46 \\
Soy-based drink D & $26.3 \pm 0.8$ & 3.95 \\
Goat milk A & $0.520 \pm 0.050$ & 0.078 \\
\hline
\end{tabular}

${ }^{a}$ Considering the consume of four $250 \mathrm{~mL}$-feeding bottles by day.

of milk powder in $1 \mathrm{~L}$ ), the Mn intake by day of a child in the age of 6 months to 1 year overcome the recommended level of $1.0 \mathrm{mg}$ by day [3] when some infant formulas and soy-based drink are consumed. Considering the sensitivity of babies and children to the Mn toxicity in, the investigation and the control of the Mn content are very necessary [7]. 
In other work, Canadian infant formula and milk samples were analyzed, and the Mn contents were reported in the range from 0.042 to $2.4 \mu \mathrm{gg}^{-1}$ in soy-based formulas and from 0.053 to $0.16 \mu \mathrm{g} \mathrm{g}^{-1}$ in milk-based formulas [22].

\section{Conclusions}

It was possible to determine $\mathrm{Mn}$ in the dairy food with the proposed method. The chemical modification was very important and the use of Ir (permanent modifier) permitted the direct determination of manganese in undigested milk and similar food samples. The multivariate optimization was an adequate tool to obtain the optimal conditions from a few experiments. The parameters of merit were satisfactory, and there were good agreement with certified materials. The Mn concentration in some samples of soy-based drink samples and infant formula was very higher than whole milk, milkbased drink, and goat milk. In this case, other studies could be realized to evaluate the risk for children.

\section{Acknowledgments}

The authors are grateful for the financial support of the Conselho Nacional de Desenvolvimento Científico e Tecnológico $(\mathrm{CNPq})$, for the technical support of the Centro de Desenvolvimento da Tecnologia Nuclear (CDTN/CNEN), and Fundação de Amparo a Pesquisa do Estado de Minas Gerais (FAPEMIG).

\section{References}

[1] S. Oga, Fundamentos de Toxicologia, Atheneu Editora, São Paulo, Brazil, 2008.

[2] S. B. Goldhaber, "Trace element risk assessment: essentiality vs. toxicity," Regulatory Toxicology and Pharmacology, vol. 38, no. 2, pp. 232-242, 2003.

[3] F. A. de Azevedo and A. A. M. Chasin, Metais: Gerenciamento da Toxicidade, Atheneu Editora, São Paulo, Brazil, 2003.

[4] R. G. Jensen, Handbook of Milk Composition, Academic Press, San Diego, Calif, USA, 1995.

[5] Agency for Toxic Substances and Disease Registry (ATSDR), Toxicological Profile for Manganese, Agency for Toxic Substances and Disease Registry (ATSDR), Atlanta, Ga, USA, 2000.

[6] K. M. Erikson, K. Thompson, J. Aschner, and M. Aschner, "Manganese neurotoxicity: a focus on the neonate," Pharmacology and Therapeutics, vol. 113, no. 2, pp. 369-377, 2007.

[7] S. J. Garcia, K. Gellein, T. Syversen, and M. Aschner, "Iron deficient and manganese supplemented diets alter metals and transporters in the developing rat brain," Toxicological Sciences, vol. 95, no. 1, pp. 205-214, 2007.

[8] E. J. B. N. Cardoso, R. B. Navarro, and M. A. Nogueira, "Changes in manganese uptake and translocation by mycorrhizal soybean under increasing Mn doses," Revista Brasileira de Ciências do Solo, vol. 27, no. 3, pp. 415-423, 2003.

[9] S. Turan, A. Saygi, Z. Kiliç, and O. Acar, "Determination of heavy metal contents in human colostrum samples by electrothermal atomic absorption spectrophotometry," Journal of Tropical Pediatrics, vol. 47, no. 2, pp. 81-85, 2001.

[10] M. Leotsinidis, A. Alexopoulos, and E. Kostopoulou-Farri, "Toxic and essential trace elements in human milk from Greek lactating women: association with dietary habits and other factors," Chemosphere, vol. 61, no. 2, pp. 238-247, 2005.

[11] P. J. McKinstry, H. E. Indyk, and N. D. Kim, “The determination of major and minor elements in milk and infant formula by slurry nebulisation and inductively coupled plasmaoptical emission spectrometry (ICP-OES)," Food Chemistry, vol. 65, no. 2, pp. 245-252, 1999.

[12] H. Matusiewicz and B. Golik, "Simultaneous determination of macro and trace elements in biological reference materials by microwave induced plasma optical emission spectrometry with slurry sample introduction," Spectrochimica Acta-Part B Atomic Spectroscopy, vol. 59, no. 5, pp. 749-754, 2004.

[13] C. Cabrera, M. L. Lorenzo, C. De Mena, and M. C. Lopez, "Chromium, copper, iron, manganese, selenium and zinc levels in dairy products: in vitro study of absorbable fractions," International Journal of Food Sciences and Nutrition, vol. 47, no. 4, pp. 331-339, 1996.

[14] E. R. Pereira-Filho, R. J. Poppi, and M. A. Z. Arruda, "Employment of factorial design for optimization of pirolisys and atomization temperatures for $\mathrm{Al}, \mathrm{Cd}, \mathrm{Mo}$ and $\mathrm{Pb}$ determination by ETAAS," Quimica Nova, vol. 25, no. 2, pp. 246-253, 2002.

[15] S. L. C. Ferreira, R. M. de Jesus, G. D. Matos et al., "Multivariate optimization and validation of an analytical method for the determination of cadmium in wines employing ET AAS," Journal of the Brazilian Chemical Society, vol. 20, no. 4, pp. 788-794, 2009.

[16] F. R. de Amorim, C. Bof, M. B. Franco, J. B. B. Da Silva, and C. C. Nascentes, "Comparative study of conventional and multivariate methods for aluminum determination in soft drinks by graphite furnace atomic absorption spectrometry," Microchemical Journal, vol. 82, no. 2, pp. 168-173, 2006.

[17] F. R. de Amorim, M. B. Franco, C. C. Nascentes, and J. B. B. da Silva, "Direct determination of molybdenum in milk and infant food samples using slurry sampling and graphite furnace atomic absorption spectrometry," Food Analytical Methods, vol. 41, no. 1, pp. 41-48, 2011.

[18] P. Peralta-Zamora, J. L. de Morais, and N. Nagata, "Por que otimização multivariada?” Engenharia Sanitária e Ambiental, vol. 10, no. 2, pp. 106-110, 2005.

[19] J. B. B. Da Silva, M. A. M. Da Silva, A. J. Curtius, and B. Welz, "Determination of $\mathrm{Ag}, \mathrm{Pb}$ and $\mathrm{Sn}$ in aqua regia extracts from sediments by electrothermal atomic absorption spectrometry using $\mathrm{Ru}$ as a permanent modifier," Journal of Analytical Atomic Spectrometry, vol. 14, no. 11, pp. 1737-1742, 1999.

[20] E. C. Lima, F. Barbosa Jr., and F. J. Krug, "Lead determination in slurries of biological materials by ETAAS using a W-Rh permanent modifier," Fresenius Journal of Analytical Chemistry, vol. 369, no. 6, pp. 496-501, 2001.

[21] M. C. Hsiang, Y. H. Sung, and S. D. Huang, "Direct and simultaneous determination of arsenic, manganese, cobalt and nickel in urine with a multielement graphite furnace atomic absorption spectrometer," Talanta, vol. 62, no. 4, pp. 791-799, 2004.

[22] R. W. Dabeka and A. D. Mckenzie, "Graphite-furnace atomicabsorption spectrometric determination and survey of total aluminum, copper, manganese, molybdenum, and tin in infant formulas and evaporated milks," Journal of AOAC International, vol. 75, no. 6, pp. 954-963, 1992. 


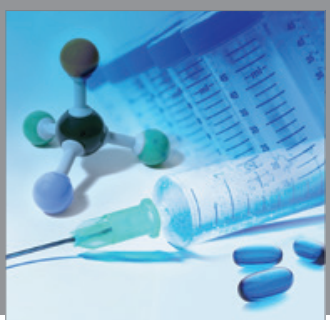

International Journal of

Medicinal Chemistry

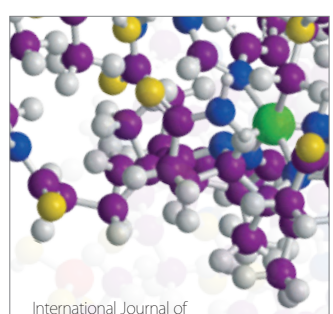

Carbohydrate Chemistry

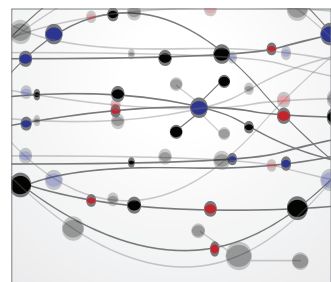

The Scientific World Journal
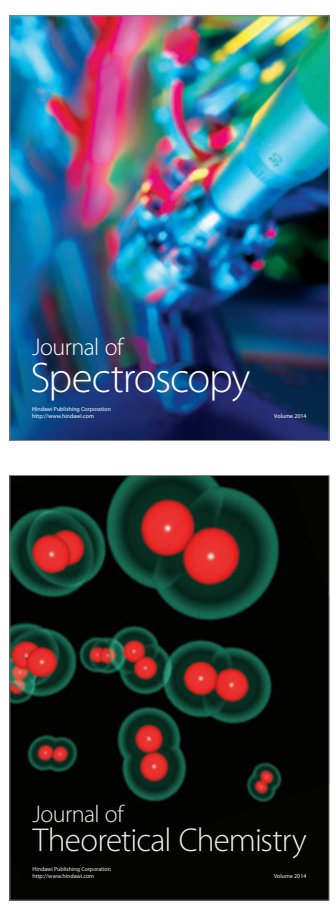
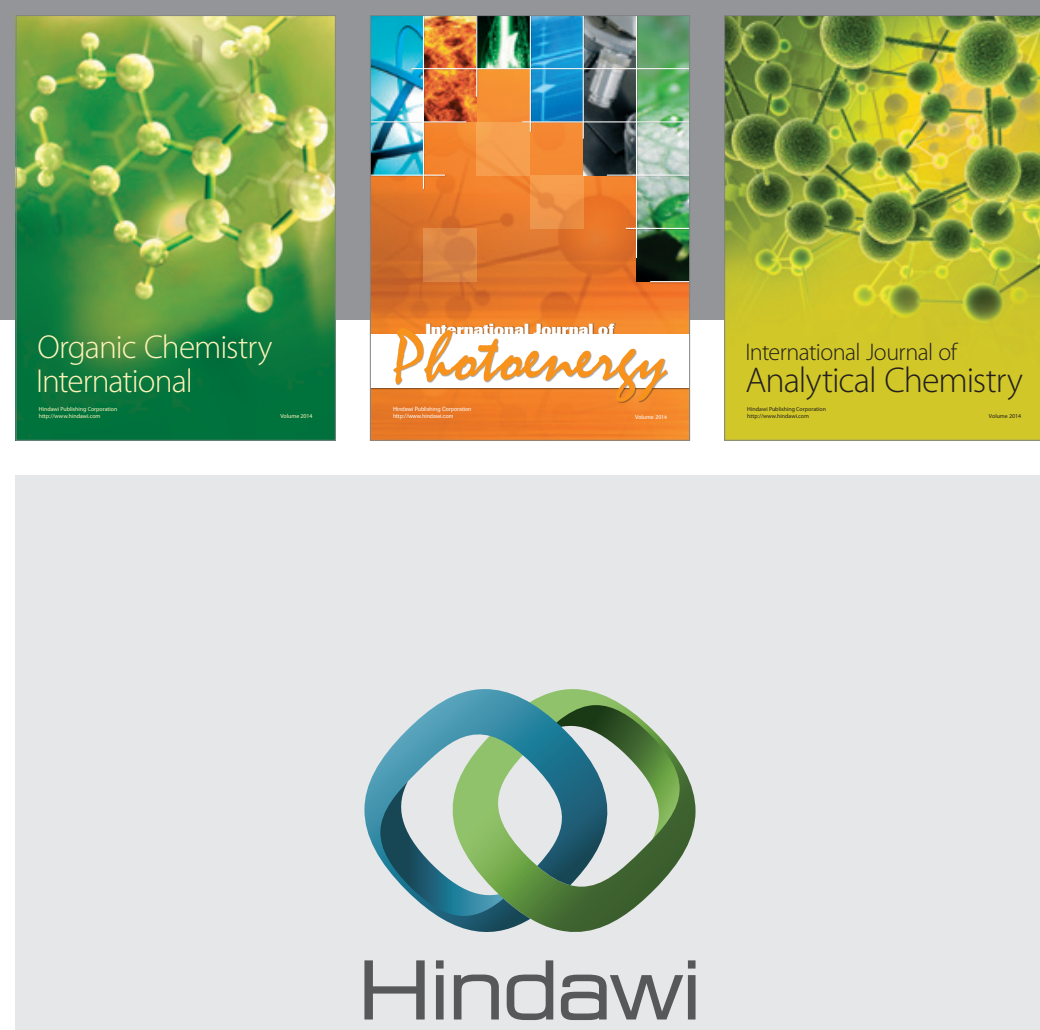

Submit your manuscripts at

http://www.hindawi.com
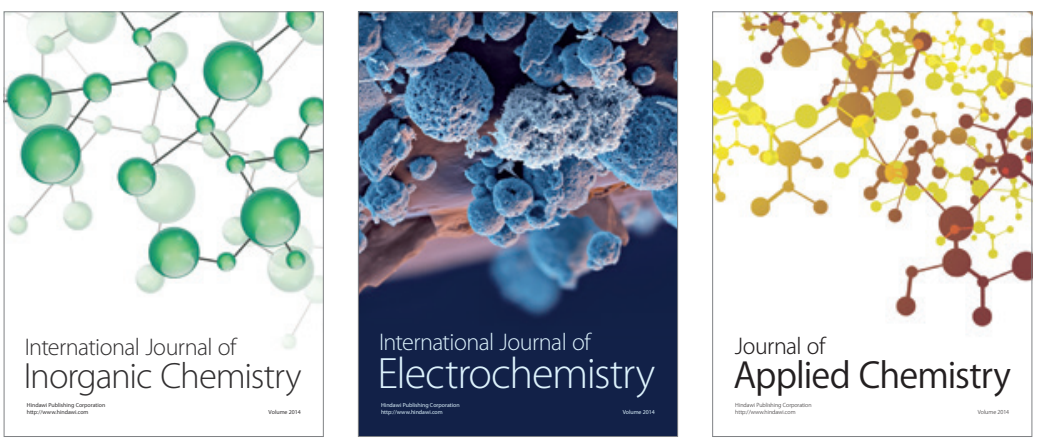

Journal of

Applied Chemistry
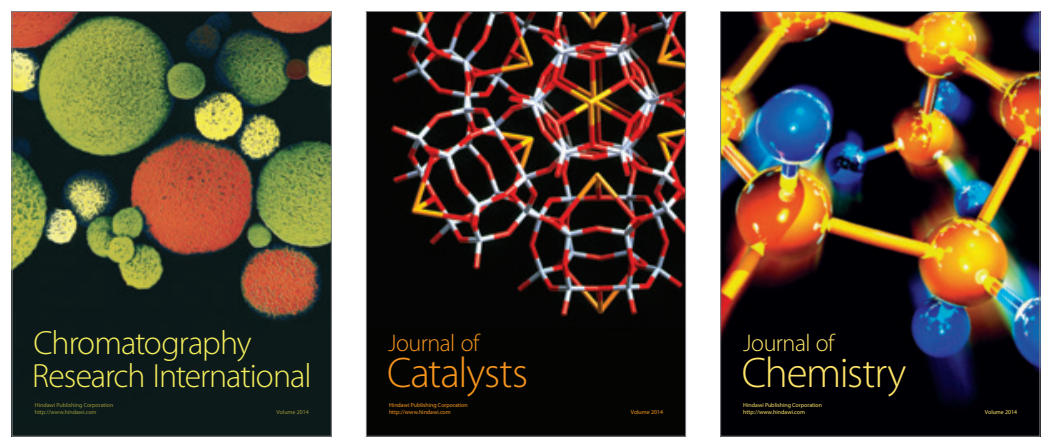
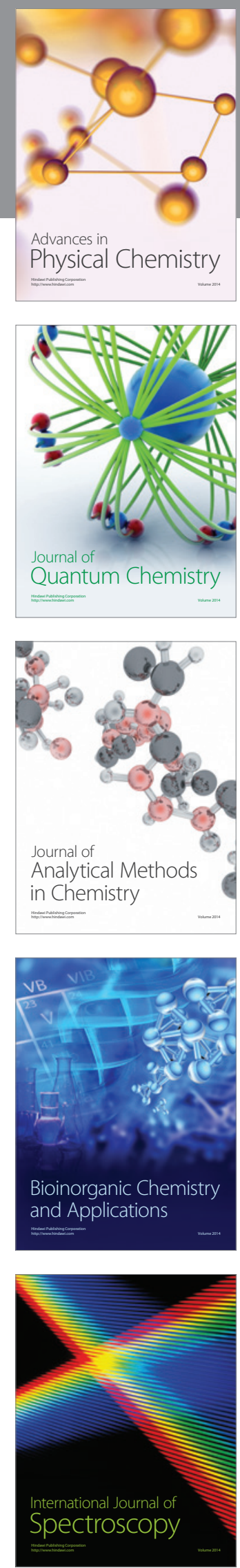